\title{
Potentiometric Determination of Cyanide in Polluted Water Samples Using Screen-Printed Electrode modified with Ruthenium(II) Complexes Ionophores
}

\author{
Tamer Awad Ali , Gehad G. Mohamed ${ }^{2,3}$, Amr L Saber ${ }^{4,5,}$, Layla S. Almazroai ${ }^{5}$ \\ ${ }^{1}$ Egyptian Petroleum Research Institute (EPRI), 11727, Cairo, Egypt. \\ ${ }^{2}$ Chemistry Department, Faculty of Science, Cairo University, 12613, Giza, Egypt. \\ ${ }^{3}$ Egypt Nanotechnology Center, Elsheikh Zayed, $6{ }^{\text {th }}$ October City, Giza, Egypt. \\ ${ }^{4}$ Chemistry Department, Faculty of Science, Zagazig University, Zagazig, Egypt. \\ ${ }^{5}$ Chemistry Department, Faculty of Science, Umm Al Qura University, Makkah, Saudi Arabia \\ *E-mail: alshefny@yahoo.com
}

doi: $10.20964 / 2017.12 .26$

Received: 27 July 2017 / Accepted: 28 September 2017 / Published: 12 November 2017

This paper reported a potentiometric cyanide sensors, based on the use of cis-(4-nitrobenzonitrile)-bis(2,2'-bipyridyl)ruthenium(II)hexafluorophosphate (ionophore A) and cis-(3-formylbenzonitrile)-bis(2,2'-bipyridyl)ruthenium(II)hexafluorophosphate (ionophore B). The sensors are prepared by incorporating of A and B ionophores into plasticized screen-printed sensors to form electrodes I and II, respectively. The best performance was obtained with a paste composition of graphite: $o$-NPOE:PVC: ionophore (A or B) ratio (w/w, mg) of 472.5:200:220:7.5. Significantly, the sensors exhibited enhanced selectivity toward cyanide ion over the concentration range $5.0 \times 10^{-6}-1.0 \times 10^{-2}$ and $2.0 \times$ $10^{-6}-1.0 \times 10^{-2} \mathrm{~mol} \mathrm{~L}^{-1}$ with a lower detection limit of $5.0 \times 10^{-6}$ and $2.0 \times 10^{-6} \mathrm{~mol} \mathrm{~L}^{-1}$ and a Nernstian slope of $58.57 \pm 0.88$ and $59.09 \pm 0.31 \mathrm{mV}$ decade $^{-1}$ at $\mathrm{pH}$ range from 3.0 to 8.0 and 3.0 to 9.0 for electrodes I and II, respectively. Influence of the paste composition and possible interfering ions on the response properties of the electrodes was investigated. Fast and stable response, good reproducibility and long-term stability are demonstrated. The sensors showed response time of <13 and $9 \mathrm{~s}$ and can be used for about 170 and 190 days without any considerable divergence in their potential response for electrodes I and II, respectively. Selectivity coefficients determined by fixed interference method (FIM) indicated high selectivity for cyanide ion. The proposed sensors showed fairly good discrimination of cyanide from many metal ions. This method was successfully applied for potentiomertric determination of cyanide in environmental samples, and the results obtained agreed with those obtained with liquid chromatography (HPLC).

Keywords: Screen-printed sensor; Selectivity; Environmental samples; cyanide determination; ruthenium(II) complexes ionophores 


\section{FULL TEXT}

(C) 2017 The Authors. Published by ESG (www.electrochemsci.org). This article is an open access article distributed under the terms and conditions of the Creative Commons Attribution license (http://creativecommons.org/licenses/by/4.0/). 